DOI: https://doi.org/10.47405/mjssh.v6i11.1158

\begin{tabular}{|c|c|}
\hline & Malaysian Journal of Social Sciences and Humanities (MJSSH) \\
\hline Malaysian Journal of & Volume 6, Issue 11, November 2021 \\
\hline (Mulssh) & e-ISSN : 2504-8562 \\
\hline & $\begin{array}{l}\text { Journal home page: } \\
\text { www.msocialsciences.com }\end{array}$ \\
\hline
\end{tabular}

\title{
Amalan Kepimpinan Instruksional dalam Menjana Pengetahuan Teknologi Pedagogi Kandungan (PTPK) di kalangan Guru
}

\author{
Aidawati Abd Rahman'1 \\ ${ }^{1}$ Fakulti Pendidikan, Universiti Malaya (UM), Malaysia \\ Correspondence: Aidawati Abd Rahman (cikguaida02@gmail.com)
}

\begin{abstract}
Abstrak
Amalan kepimpinan instruksional dan pengintegrasian teknologi dalam pengajaran dan pembelajaran merupakan dua amalan yang memberi impak dalam memastikan kelestarian proses pendidikan. Keduadua elemen ini diadaptasi bagi memastikan kesinambungan pendidikan diteruskan dengan menggunakan sumber sedia ada bagi mencari solusi baharu dengan meminimumkan risiko dan juga mengurangkan kos. Oleh itu, kertas konsep ini bertujuan mengenal pasti amalan kepimpinan instruksional dalam mempengaruhi pengetahuan teknologi pedagogi kandungan (PTPK) di kalangan guru-guru sekolah menengah di Malaysia. Tiga dimensi dalam amalan kepimpinan instruksional (mentakrif matlamat sekolah, mengurus program instruksional, menggalakkan iklim sekolah yang positif) dikenal pasti mempunyai hubungan yang signifikan terhadap amalan mengintegrasikan teknologi dalam pengajaran dan pembelajaran iaitu merujuk kepada kerangka PTPK. Justeru, analisis kajian ini mencadangkan struktur model hubungan menggunakan Structural Equation Modelling (SEM). Hipotesis kajian dibentuk berasaskan literatur dan cadangan kerangka konseptual. Kajian ini keseluruhannya memberi implikasi berkaitan kepentingan menyediakan pemimpin sekolah dengan kemahiran mengurus program instruksional bagi membina pengetahuan teknologi pedagogi kandungan (PTPK) di kalangan guru serta menggalakkan iklim sekolah yang positif.
\end{abstract}

Kata kunci: kepimpinan instruksional, pengetahuan teknologi pedagogi kandungan

\section{Instructional Leadership Practices in Generating Technological Pedagogical and Content Knowledge (TPACK) Among Teachers}

\begin{abstract}
The practice of instructional leadership and the integration of technology in teaching and learning are two practices that have an impact in ensuring the sustainability of the educational process. Both of these elements are adapted to ensure the continuity of education by using existing resources to find new solutions by minimizing risks and also reducing costs. Therefore, this concept paper aims to identify instructional leadership practices in influencing the technological pedagogical and content knowledge (TPACK) among secondary school teachers in Malaysia. Three dimensions in instructional leadership practice (defining school goals, managing instructional programs, promoting a positive school climate) were identified to have a significant relationship to the practice of integrating technology in teaching and learning i.e. referring to the TPACK framework. Thus, the analysis of this study suggests a relationship model structure using Structural Equation Modeling (SEM). The research hypotheses were formed based on the literature and the proposed conceptual framework. This study as a whole gives implications related to the importance of providing school leaders with the skills to manage
\end{abstract}


instructional programs to build technological pedagogical and content knowledge (TPACK) among teachers and promote a positive school climate.

Keywords: instructional leadership, technological pedagogical and content knowledge

\section{Pengenalan}

Penutupan sekolah di seluruh negara kesan daripada kes positif COVID-19 yang meningkat telah menjadi peristiwa penting dalam sejarah negara termasuklah bidang pendidikan. Penangguhan peperiksaan awam pada tahun 2020 dan 2021 menggesa para guru untuk mempertimbangkan semula kaedah pengajaran dan pembelajaran (PdP) yang terjejas sejak Perintah Kawalan Pergerakan (PKP) dilaksanakan supaya dapat berfungsi seperti biasa. Kebanyakan negara telah melakukan perubahan dalam pelaksanaan pendidikan secara komprehensif dengan memperkasakan pendidikan digital (Pozo et al., 2021).

Profesion perguruan sentiasa berubah seiring dengan keperluan pendidikan pada masa kini. Pengetahuan dan kebolehan guru perlu dipertingkatkan bagi menambah baik amalan pengajaran bagi memenuhi pembelajaran murid. Perkembangan pesat teknologi yang sentiasa berubah memberi impak dan cabaran buat para guru untuk mengaplikasikan teknologi di bilik darjah. Justeru, para guru dijangkakan dapat melaksanakan pengajaran dengan menyesuaikan penggunaan teknologi, pedagogi dan kandungan dengan baik (Barton \& Dexter, 2020). Pendidikan yang melibatkan teknologi digital merupakan transformasi terkini sistem pendidikan, terutamanya semasa penularan wabak COVID-19 di seluruh dunia. Kementerian Pendidikan Malaysia (KPM) telah mengambil inisiatif untuk menerajui usaha mengembangkan kemahiran dan potensi guru serta murid dalam penggunaan teknologi digital.

Dunia pendidikan semakin mencabar, terutama pada era digital yang menuntut agar pemimpin sekolah memupuk penggunaan teknologi digital dalam pentadbiran dan pengurusan sekolah. Kementerian Pendidikan Malaysia (KPM) telah menghasilkan Pelan Transformasi ICT 2019-2023, yang dilancarkan untuk menyokong agenda pendidikan digital di Malaysia (Kementerian Pendidikan Malaysia, 2015). Pentadbir sekolah digesa untuk menguasai kemahiran teknologi digital, termasuk memiliki ciri kepimpinan yang berfokus kepada teknologi digital (Yusof et al., 2019). Para guru juga digalakkan untuk menguasai kemahiran teknologi digital agar tidak mengalami kesukaran dalam melaksanakannya perubahan pendidikan (N. H. Hamzah et al., 2021). Oleh itu, untuk mencapai matlamat Pelan Transformasi ICT 2019-2023 pengetua sekolah serta guru-guru perlulah menggunakan kemahiran ICT untuk meningkatkan prestasi akademik murid dan mengaplikasikan pendekatan pedagogi berasaskan teknologi digital. Pengetua yang ingin melaksanakan kepimpinan digital perlu menggunakan ruang dan peluang mereka dengan bijak untuk membawa perubahan yang besar dalam budaya sekolah agar dapat memberi impak positif terhadap sistem pendidikan di Malaysia, yang bertujuan untuk menggunakan elemen teknologi dan penguasaan digital untuk meningkatkan kebolehpasaran pelajar dalam era pendidikan 4.0 (Shulla et al., 2021). Pengetua perlu mengenal pasti pendekatan terbaik untuk memastikan penglibatan berkesan guru dan murid (Arokiasamy et al., 2014; Ismail et al., 2018). Menurut (Raman et al., 2019), tanggungjawab guru menjadi lebih kompleks kerana mereka harus komited untuk mencari pelbagai alternatif untuk menyokong integrasi teknologi digital dalam proses pengajaran dan pembelajaran.

Kajian oleh Qadach et al. (2020) berpendapat dua asas utama bagi menentukan kejayaan sesuatu dasar baharu melibatkan kepimpinan pentadbiran sekolah menggunakan kebijaksanaan melakukan transformasi terhadap guru-guru dan bagaimana mereka memainkan peranan untuk mendapatkan sokongan daripada organisasi sekolah. Literatur kajian ini disokong dengan hasil kajian Ma dan Marion (2021) yang menunjukkan amalan kepimpinan pemimpin sekolah mempengaruhi prestasi kerja guru. Ini berikutan polisi pentadbir sekolah mempengaruhi komitmen kerja guru. Oleh itu, berdasarkan peranan penting seseorang pemimpin instruksional menggembleng tenaga menggerakkan warga sekolah, maka penyelidik ingin mengkaji kesan pengaruh kepimpinan instruksional dalam mempengaruhi pengajaran guru di sekolah menengah. 
Oleh yang demikian, cadangan kerangka konsep dalam kajian ini mampu memberi panduan kepada Bahagian Pendidikan Guru (BPG), Jabatan Pendidikan Negeri (JPN), pihak pentadbir dalam merancang dan mengatur program kepimpinan instruksional yang mengintegrasikan teknologi digital agar dapat menggalakkan amalan pengajaran guru yang lebih berkesan melalui pelbagai medium digital seterusnya meningkatkan prestasi akademik murid, walaupun ketika krisis pandemik COVID19. Kajian ini diharapkan dapat memberi sumbangan idea kepada Bahagian Pendidikan Guru (BPG) yang berperanan sebagai peneraju utama dalam pendidikan guru dengan mengambil kira analisis kajian agar dapat merangka keperluan kursus dalam meningkatkan kualiti guru dan memastikan pemantapan kualiti pengajaran dan pembelajaran secara digital.

Justeru, kertas konsep ini bertujuan untuk mengenal pasti elemen-elemen dalam amalan kepimpinan instruksional pengetua melalui tiga dimensi (mentakrif matlamat sekolah, mengurus program instruksional, menggalakkan iklim sekolah yang positif) yang dapat meramalkan amalan pengajaran digital di kalangan guru-guru melalui tiga dimensi utama PTPK (pengetahuan pedagogi, pengetahuan kandungan dan pengetahuan teknologi).

\section{Sorotan Literatur}

Melalui penggubalan Pelan Pembangunan Pendidikan Malaysia (PPPM) 2013-2025, kementerian turut memastikan setiap sekolah diterajui oleh pemimpin berprestasi tinggi bagi memastikan kelestarian transformasi sistem pendidikan negara dapat dilaksanakan dengan baik. PPPM turut memberi tumpuan kepada amalan kepimpinan instruksional supaya peranan sebagai pemimpin instruksional dapat dilaksanakan secara realistik dan menjadi indikator penentu kepada kecemerlangan pendidikan. Menurut Hallinger dan Hosseingholizadeh (2020) elemen terpenting dalam menentukan kepimpinan yang berkesan dalam sesebuah organisasi pendidikan adalah kebolehan seseorang pemimpin melaksanakan tugas sebagai pemimpin instruksional. Sebagai seorang pemimpin instruksional, adalah menjadi tanggungjawab memastikan kualiti pengajaran dan pembelajaran guru di sekolah dapat menjamin kecemerlangan pencapaian murid. Sekolah yang dipimpin oleh seorang pengetua yang berkesan, mampu memberi dorongan dan motivasi kepada guru-guru untuk menyampaikan pengajaran dengan baik (Hussin, 2019). Manakala murid memerlukan guru yang berkualiti dalam memperoleh pengetahuan dan membina kemahiran di dalam bilik darjah. Oleh itu, keberkesanan sesebuah sekolah bergantung kepada kepimpinan instruksional pengetuanya dan juga kualiti pengajaran para guru (Hallinger et al., 2013).

Lantaran itu, Pelan Transformasi ICT (2019-2023) dilancarkan untuk menyokong agenda pendidikan digital di Malaysia agar pemimpin sekolah memupuk penggunaan teknologi dalam pentadbiran dan pengurusan sekolah (Kementerian PendidikanMalaysia, 2015). Pemimpin instruksional yang cenderung untuk menerapkan teknologi digital perlu menggunakan ruang dan peluang yang ada untuk membawa perubahan besar kepada budaya sekolah. Ini akan memberi kesan positif terhadap sistem pendidikan di Malaysia, yang bertujuan untuk menggunakan elemen teknologi dan penguasaan digital untuk meningkatkan kebolehpasaran murid dalam era pendidikan 4.0 (Shulla et al., 2021).

Pengetua perlu mengenal pasti pendekatan terbaik untuk memastikan penglibatan berkesan guru dan murid (Arokiasamy et al., 2014). Menurut Raman et al. (2019), tanggungjawab guru menjadi lebih kompleks, kerana mereka harus komited untuk mencari pelbagai alternatif untuk menyokong amalan dalam mengintegrasikan teknologi digital dalam pengajaran dan pembelajaran. Menurut Hamzah et al. (2019) murid bersemangat untuk belajar menggunakan medium digital dan penggunaan peranti seperti telefon bimbit, tablet dan sebagainya.

Walau bagaimanapun, menurut Mei Wei et al. (2016) masih terdapat sebilangan pemimpin sekolah yang enggan menggunakan teknologi digital, seperti menolak kelebihan media sosial dan penggunaan peranti digital kerana tidak menguasai teknologi ICT. Namun, hasil kajian Mei Wei et al. (2016) menunjukkan terdapat hubungan antara pengetahuan mengenai integrasi teknologi dan kemampuan pengetua untuk memotivasikan diri mereka untuk melaksanakan perubahan keseluruhan sekolah. Amels et al. (2020) juga berpendapat bahawa pengetua merupakan pemimpin yang perlu memulakan 
dan menyokong integrasi teknologi dalam pendidikan dengan memodelkan dan memasukkan teknologi ke dalam amalan kepimpinan instruksional mereka. Menurut (Karahan et al., 2015), adalah menjadi keperluan pemimpin sekolah mengikuti perkembangan teknologi bagi memastikan kelestarian pendidikan terutamanya dalam norma baharu pendidikan. Oleh itu, kertas konsep ini bertujuan mengenal pasti elemen-elemen kepimpinan instruksional dalam mempengaruhi pengetahuan teknologi pedagogi kandungan (PTPK) di kalangan guru-guru sekolah menengah di Malaysia.

\section{Kepimpinan Instruksional}

Kepimpinan instruksional adalah konsep kepimpinan yang melibatkan tindakan dan aktiviti yang dilaksanakan oleh pemimpin sekolah secara langsung mempengaruhi pencapaian murid. Pengetua yang berperanan sebagai tonggak utama pemimpin instruksional di sekolah perlu mempunyai pengetahuan yang berkaitan dengan teori dan model kepimpinan instruksional dalam membantu tugas dan urusan mereka di sekolah. Kajian yang berkaitan dengan kepimpinan instruksional telah dimulakan sejak awal tahun 1920-an yang berkaitan dengan sekolah berkesan dan peningkatan sekolah serta tingkah laku kepimpinan pengetua yang dikenal pasti sebagai faktor utama dalam menentukan pencapaian akademik di sebuah sekolah dalam menghasilkan modal insan yang cemerlang (Hassan \& Jamilah Ahmad, 2019). Oleh itu, kepimpinan instruksional merujuk kepada Model Kepimpinan Instruksional oleh Heck dan Hallinger (2014) yang menjadi asas pembinaan teori kajian ini. Model ini menerangkan tiga fokus utama yang perlu dilakukan oleh pengetua sebagai pemimpin instruksional yang bermula dengan; menentukan matlamat sekolah; menguruskan program instruksional di dalam bilik darjah sehingga peranan pengetua untuk menggalakkan iklim sekolah yang positif agar dapat menyumbang kepada peningkatan pencapaian murid. Menurut (Hallinger et al., 2013b), model ini menekankan penglibatan dan hubungan antara pengetua dan warga sekolah dalam mempengaruhi pencapaian akademik murid.

Hallinger et al. (2013a) telah membuat modifikasi model dan konsep dari model sebelumnya Hallinger dan Murphy (1987). Penambahbaikan terhadap definisi kepimpinan instruksional sebagai pemimpin yang mengutamakan definisi matlamat sekolah, menguruskan program instruksional dan menggalakkan iklim sekolah yang positif. Hallinger et al. (2013a) telah menggugurkan sub-dimensi penguatkuasaan standard akademik yang terkandung dalam dimensi mempromosikan iklim sekolah. Namun tiga dimensi fokus utama dipertahankan iaitu mentakrif matlamat sekolah, mengurus program instruksional dan menggalakkan iklim sekolah yang positif. Model kepimpinan instruksional ini diringkaskan seperti pada jadual 1.

Jadual 1: Model Kepimpinan Instruksional oleh (Hallinger, 2018)

\begin{tabular}{|c|c|c|}
\hline $\begin{array}{l}\text { Mentakrif matlamat } \\
\text { sekolah }\end{array}$ & $\begin{array}{l}\text { Mengurus Program } \\
\text { instruksional }\end{array}$ & $\begin{array}{l}\text { Menggalakkan iklim sekolah yang } \\
\text { positif }\end{array}$ \\
\hline $\begin{array}{l}\text { - Merangka matlamat } \\
\text { sekolah yang jelas } \\
\text { - Menyampaikan } \\
\text { matlamat sekolah } \\
\text { dengan jelas }\end{array}$ & $\begin{array}{l}\text { - Menyelia dan membuat } \\
\text { penilaian instruksional } \\
\text { - Menyelaras kurikulum } \\
\text { - Memantau perkembangan } \\
\text { murid }\end{array}$ & $\begin{array}{l}\text { - Melindungi masa instruksional } \\
\text { - Menggalakkan pembangunan } \\
\text { profesional } \\
\text { - Mengekalkan sokongan pembelajaran } \\
\text { - Menyediakan insentif untuk guru } \\
\text { - Menyediakan insentif untuk murid }\end{array}$ \\
\hline
\end{tabular}

Hallinger et al. (2013a) menyatakan pengetua sebagai pemimpin di sekolah perlu bekerjasama untuk merangka matlamat sekolah yang berkaitan dengan pencapaian murid. Seorang pengetua harus merangka matlamat yang memberi inspirasi dan mencapai kata sepakat untuk mencapai tujuan tersebut. Matlamat bersama akan memotivasikan seluruh warga sekolah dalam menyokong peningkatan pencapaian murid. Heck dan Hallinger (2014) juga membuktikan bahawa pembinaan matlamat sekolah yang difokuskan dan dikongsi akan mempengaruhi pencapaian murid. Oleh itu, matlamat sekolah yang digubal oleh pengetua mesti difahami dan dilaksanakan oleh guru dan harus dijelaskan kepada setiap anggota sekolah, termasuk murid dan ibu bapa.

Dimensi kedua iaitu menguruskan program instruksional memerlukan penglibatan guru secara langsung dalam kurikulum dan proses pengajaran. Hallinger et al. (2013a) mendefinisikan mengurus 
program instruksional sebagai menyelia dan menilai program, menyelaraskan kurikulum dan memantau perkembangan murid. Peranan pengetua adalah memastikan matlamat sekolah dapat diterjemahkan menjadi amalan di dalam kelas dan memantau pencapaian murid dalam usaha memantapkan semua program akademik yang dilaksanakan. Melalui pemantauan pencapaian murid, pengetua dan guru dapat membincangkan dan mengenal pasti kekuatan dan kelemahan murid dan kemudian merancang program yang dapat meningkatkan prestasi mereka.

Dimensi ketiga adalah untuk menggalakkan iklim sekolah yang positif merujuk kepada norma dan tingkah laku guru dan murid yang mempengaruhi proses pembelajaran di sekolah. Seorang pengetua mampu mempengaruhi iklim pembelajaran secara langsung atau tidak langsung dengan menguasai kemahiran untuk berkomunikasi, berbincang dan memberi ruang untuk mendekati guru dan murid, menyediakan sistem insentif sebagai usaha menggalakkan produktiviti organisasi sekolah.

\section{Pengetahuan Teknologi Pedagogi Kandungan (PTPK)}

Model Pengetahuan Teknologi Pedagogi Kandungan (PTPK) seperti rajah 1 berikut, menjelaskan elemen pengetahuan yang diperlukan oleh seseorang guru untuk mengintegrasikan Pengetahuan Teknologi (PT), Pengetahuan Pedagogi (PP) dan Pengetahuan Kandungan (PK) dalam pengajaran. Kerangka model PTPK ini merupakan hasil daripada perkembangan idea yang dikemukakan oleh Shulman (1986) iaitu Model Pengetahuan Pedagogi Kandungan (PPK). Menurut Koehler et al. (2014), TPACK merupakan elemen yang hanya dimiliki oleh seseorang guru. Menurutnya lagi, pengetahuan tentang teknologi sangat penting pada masa kini kerana ianya tidak boleh dianggap sebagai elemen bebas, dan pengajaran yang baik memerlukan pemahaman tentang bagaimana teknologi berkaitan dengan pengetahuan pedagogi dan kandungan kurikulum yang diajar.

Rajah 1. Model Pengetahuan Teknologi Pedagogi Kandungan (PTPK)

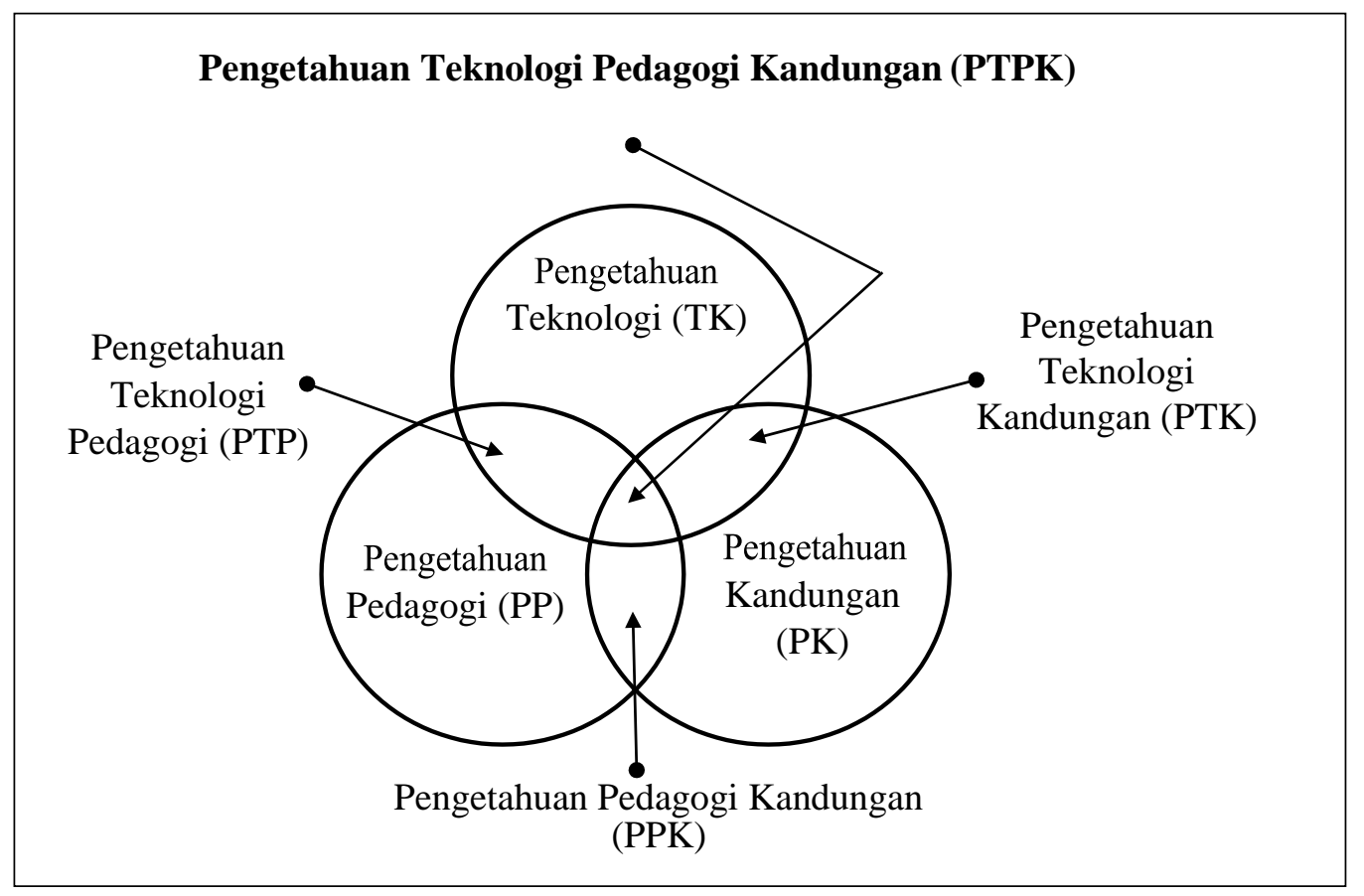

Sumber: Diadaptasi daripada Koehler et al. (2014)

Secara umumnya, model PTPK ini terdiri daripada tujuh elemen hasil integrasi pengetahuan kandungan, pedagogi dan teknologi iaitu; (i) Pengetahuan Kandungan (PK), (ii) Pengetahuan Pedagogi (PP), (iii) Pengetahuan Teknologi (PT), (iv) Pengetahuan Pedagogi Kandungan (PPK), (v) Pengetahuan Teknologi Kandungan (PTK), (vi) Pengetahuan Teknologi Pedagogi (PTP) dan (vii) Pengetahuan Teknologi Pedagogi Kandungan (PTPK). Mishra dan Koehler (2006) menekankan integrasi ketujuhtujuh elemen ini dalam pengajaran guru bagi menghasilkan PdP yang efektif dan sempurna bagi 
seseorang guru atau pengajar. Walaupun terdapat tujuh elemen pengetahuan dalam model TPACK ini, tiga elemen utama yang mendasari PTPK adalah Pengetahuan Kandungan (PK), Pengetahuan Pedagogi (PP) dan Pengetahuan Teknologi (PT). Kefahaman ketiga-tiga elemen ini penting dalam usaha membuat persediaan yang mencukupi agar dapat memenuhi tuntutan dan jangkaan keperluan pendidikan dan masyarakat untuk mengintegrasikan teknologi dalam pengajaran (Cathrine Masingan \& Sabariah Sharif, 2019).

\section{Hubungan Kepimpinan Instruksional dan Pengetahuan Teknologi Pedagogi Kandungan (PTPK)}

Mendepani cabaran Industri 4.0, sistem pendidikan di Malaysia turut mengubah kurikulum secara berperingkat mulai tahun 2017. Transformasi terhadap Kurikulum Standard Sekolah Rendah (KSSR) serta Kurikulum Standard Sekolah Menengah (KSSM) melibatkan perubahan dari segi jumlah jam pembelajaran bagi mata pelajaran tertentu dan juga jumlah jam dalam sesi persekolahan. Transformasi yang dilaksanakan dilihat dapat menambah baik kedua-dua kurikulum pendidikan sedia ada supaya murid berupaya memperoleh pengetahuan, kemahiran dan nilai yang relevan dengan keperluan serta cabaran abad ke-21. Sehubungan itu, pemimpin sekolah pada hari ini perlu melengkapkan diri dengan pengetahuan dan kemahiran teknologi bagi memastikan amalan pembelajaran di sekolah seiring dengan transformasi kurikulum ini (Hassan et al., 2018).

Selain sokongan pihak pemimpin instruksional, penggunaan alat bantu mengajar dalam pengajaran dan pembelajaran adalah penting untuk menarik minat murid dan meningkatkan prestasi mereka, serta mencapai objektif guru dalam mengajar sesuatu mata pelajaran (Dooley et al., 2016). Aksal (2015) telah menyatakan bahawa pentadbir sekolah perlu mengambil inisiatif untuk belajar mengintegrasikan teknologi dalam kepimpinan di sekolah termasuklah merancang program latihan guru menggunakan teknologi dan menjalankan tugas pengurusan sekolah dan kepimpinan sekolah menggunakan peranti teknologi digital. Pengurusan sistem pendidikan yang cekap oleh pengetua akan membantu memberi kesan positif terhadap amalan pengajaran guru dan sistem pembelajaran digital (Hassan \& Jamilah, 2019). Penggunaan teknologi telah menyokong pembelajaran di bilik darjah, yang membawa kepada peningkatan pencapaian murid serta merapatkan jurang pencapaian akademik murid.

Sementara itu, Arokiasamy et al. (2014) menunjukkan bahawa tidak ada hubungan yang signifikan antara kepimpinan digital pengetua dengan pelaksanaan pembelajaran digital oleh guru. Walau bagaimanapun, pengaruh kepimpinan instruksional pengetua dalam mewujudkan iklim sekolah yang positif mempunyai hubungan yang signifikan terhadap amalan mengintegrasikan teknologi dalam pengajaran dan pembelajaran (Qadach et al., 2020). Pengajaran digital adalah pengajaran yang mengintegrasikan teknologi digital dalam pembelajaran murid. Ia boleh berlaku di semua bidang kurikulum (Hamzah et al., 2021). Faktor kualiti guru penting untuk sistem pengajaran yang berkesan bagi meningkatkan pencapaian murid (Raman et al., 2019). Salah satu petunjuk kualiti guru adalah penguasaan kecekapan digital. Kajian oleh Domeny (2017) menunjukkan bahawa faktor utama yang menentukan kejayaan pembelajaran berasaskan digital bukan hanya fasiliti peranti digital, tetapi kecekapan yang perlu dikuasai oleh guru.

Beberapa kajian melaporkan terdapat halangan untuk mengintegrasikan teknologi digital dalam pengajaran dan pembelajaran. Ini berikutan kurangnya pengetahuan, kemahiran, latihan, dan keyakinan diri serta kemudahan yang terhad (Vinathan, 2017). Menurut Mohd Khalid dan Quick (2016), para guru tidak menggunakan masa sebaiknya untuk meneroka bahan kursus, mengoptimumkan latihan yang dihadiri dan tidak mengaplikasikan pengajaran digital di dalam bilik darjah. Laporan oleh Organization for Economic Cooperation and Development (OECD) juga turut menyatakan isu pelaksanaan pengajaran dan pembelajaran secara digital menghadapi kekangan dari aspek fasiliti seperti akses dan penggunaan komputer yang terhad. Kebanyakan murid menggunakan peranti mudah alih untuk tujuan lain yang bukan bersifat pendidikan dan tahap kecenderungan mereka untuk penggunaan peranti digital ini memberi kesan terhadap prestasi yang berbeza (OECD, 2021).

Kajian lepas menunjukkan bahawa, amalan terbaik teknologi untuk pengajaran dan pembelajaran bermula dengan pengetua merupakan yang menjadi contoh teladan penggunaan teknologi yang 
berterusan dalam sesebuah institusi pendidikan (Aad et al., 2014; Clark-Wilson et al., 2020; Vazquez Cano \& Sevillano García, 2013). Seseorang pengetua yang cenderung untuk mengintegrasikan teknologi digital dalam kepimpinan instruksional mempunyai misi dan visi yang jelas bahawa ICT berpotensi untuk meningkatkan pencapaian murid. Usaha ini juga menggambarkan komitmen secara pasif seseorang pengetua bagi memastikan perkembangan profesional dalam meningkatkan kemahiran ICT guru mereka (Zhong, 2017). Afshari et al. (2008) turut menegaskan peranan utama yang perlu dimainkan oleh pengetua seperti menggalakkan sokongan teknologi dan merangka strategi intervensi dengan menyediakan fasiliti terhadap perubahan proses pengajaran dan pembelajaran. Sokongan pengetua dalam penggunaan teknologi dengan memberi keyakinan kepada para guru serta memperuntukkan sumber selain menjadualkan perkembangan profesional melalui integrasi ICT secara berkala (Hussin, 2019). Tidak dinafikan, pengetua yang berkesan perlu terlibat secara aktif dengan teknologi, termasuklah memodelkan penggunaan teknologi dan membantu melaksanakan program perkembangan staf supaya dapat mengintegrasikan teknologi dalam kurikulum.

Menurut Mei Wei et al. (2016), terdapat hubungan antara pengetahuan tentang integrasi teknologi dan kemampuan pengetua untuk memotivasikan diri mereka untuk melaksanakan perubahan di sekolah. Aad et al. (2014) juga berpendapat bahawa pengetua adalah pemimpin yang perlu memulakan dan mempertahankan penggunaan teknologi dalam pendidikan dengan memodelkan dan memasukkan teknologi ke dalam amalan pengurusan dan pentadbiran harian mereka. Zhong (2017) mendapati bahawa perlunya pentadbir sekolah untuk menyesuaikan diri dengan perkembangan teknologi terkini dalam memastikan penyampaian pengajaran guru di bilik darjah seiring dengan perkembangan semasa.

Harris et al. (2018) turut membincangkan peranan pentadbir dalam mengintegrasikan teknologi di mana pengetua perlu menggerakkan para guru mereka untuk mewujudkan budaya teknologi. Justeru, Divaharan dan Ping (2010) mencadangkan tiga peranan utama seseorang pengetua sebagai pemimpin teknologi dalam mengintegrasikan ICT dengan lebih baik di kalangan guru mereka iaitu; menjadi contoh teladan, kepimpinan instruksional berasaskan ICT, dan berwawasan. Bagi memastikan kejayaan dalam melaksanakan penggunaan ICT di kalangan guru-guru, Tibagwa et al. (2016) mencadangkan seseorang pengetua perlu menggunakan sumber sedia ada dengan bijak dan kreatif. Di samping itu, mereka perlu mewujudkan visi sekolah dalam konteks memperkasakan penggunaan teknologi di kalangan guru seterusnya membantu murid ke arah celik teknologi (Mayes et al., 2015). Dalam sebuah kajian mengenai korelasi antara persepsi guru terhadap kepimpinan teknologi pengetua dan integrasi teknologi pendidikan, Niekerk dan Wyk (2014) mendapati bahawa guru yang mempunyai persepsi positif tentang peranan pengetua dalam menyokong integrasi teknologi lebih cenderung mengaplikasikan teknologi dalam pengajaran dan pembelajaran.

Berdasarkan justifikasi yang dinyatakan di atas dapat disimpulkan bahawa, seorang pemimpin memerlukan kemahiran asas dalam mengurus dan memimpin organisasi dalam dunia globalisasi dan kemajuan teknologi hari ini. Pelbagai kemahiran dan kebolehan diperlukan dari seorang pemimpin terutama pemimpin di sekolah dalam menghadapi cabaran pengurusan dan kepimpinan pendidikan yang semakin kompleks. Oleh kerana kepimpinan melibatkan proses mempengaruhi tingkah laku dan implikasinya terhadap pengikut di bawah kepimpinannya, maka wujud hubungan timbal balik atau interaksi antara satu sama lain (pemimpin memerlukan pengikut dan sebaliknya pengikut memerlukan pemimpin), sementara Sun dan Leithwood (2017) membuktikan bahawa pengaruh kepimpinan berdasarkan empat aspek iaitu rasional, emosi, organisasi dan persekitaran. Oleh itu, sewajarnya kajian ini menyelidik elemen-elemen kepimpinan instruksional (berdasarkan teori kepimpinan instruksional) yang digunakan oleh pengetua dalam memimpin integrasi teknologi (merujuk kepada model PTPK) dalam kalangan guru agar dapat mencapai matlamat melahirkan murid yang cemerlang dan sekolah yang berkesan. Hubungan antara setiap pemboleh ubah dalam kajian ini ditunjukkan dalam rajah 3 yang menjelaskan kerangka konseptual di antara kepimpinan instruksional dan pengetahuan teknologi pedagogi kandungan (PTPK). Di samping itu, kajian ini juga dapat mengenal pasti elemen-elemen dalam kepimpinan instruksional pengetua yang dapat meramalkan pengajaran digital guru. 


\section{Cadangan Kerangka Konsep}

Berdasarkan hasil kajian lepas menunjukkan PTPK perlu difahami sebagai asas pengetahuan yang diperlukan oleh guru untuk mengajar dan memerlukan pemahaman yang mendalam untuk mengaplikasikannya ke dalam mata pelajaran tertentu. Asas pengetahuan ini perlu dibentuk berdasarkan bidang tertentu (Andyani et al., 2020; Blonder \& Rap, 2017). Penggunaan teknologi khusus perlulah bersesuaian dengan konsep pembelajaran yang kompleks agar dapat membentuk pemahaman yang konstrukstif dalam membentuk pengetahuan baru semasa proses pembelajaran murid (Mlambo et al., 2020). Selain itu, pengintegrasian teknologi berdasarkan model PTPK dan amalan kepimpinan instruksional dilihat saling berkait rapat. Amalan kepimpinan instruksional ini mempengaruhi para guru untuk menggunakan teknologi, maka konsep PTPK ini perlulah diterapkan dalam latihan pembangunan profesionalisme guru bagi meningkatkan efikasi kendiri guru menggunakan teknologi dalam proses pengajaran dan pembelajaran. Oleh itu kajian ini mencadangkan kerangka konsep seperti rajah 3 di bawah.

Kerangka konsep ini melibatkan model asas kepimpinan instruksional yang dikemukakan oleh Hallinger et al. (2013a) sebagai pemboleh ubah bebas. Tiga dimensi utama kepimpinan instruksional iaitu mentakrif matlamat sekolah, mengurus program instruksional, menggalakkan iklim sekolah yang positif. Amalan pengintegrasian teknologi di bilik darjah adalah berdasarkan model pengetahuan teknologi pedagogi kandungan yang dikemukakan oleh (Mishra \& Koehler, 2006). Model ini melibatkan tiga dimensi utama yang mendasari amalan pengintegrasian teknologi di bilik darjah iaitu Pengetahuan Kandungan (PK), Pengetahuan Pedagogi (PP) dan Pengetahuan Teknologi (PT).

Berdasarkan kajian literatur yang dibuat, kerangka konsep ini merumuskan pengaruh amalan kepimpinan instruksional sebagai (pemboleh ubah bebas) terhadap integrasi teknologi guru di dalam proses pengajaran dan pembelajaran berasaskan model PTPK (pemboleh ubah bersandar).

Rajah 2. Kerangka konseptual hubungan antara kepimpinan instruksional dan pengetahuan teknologi pedagogi kandungan (PTPK)

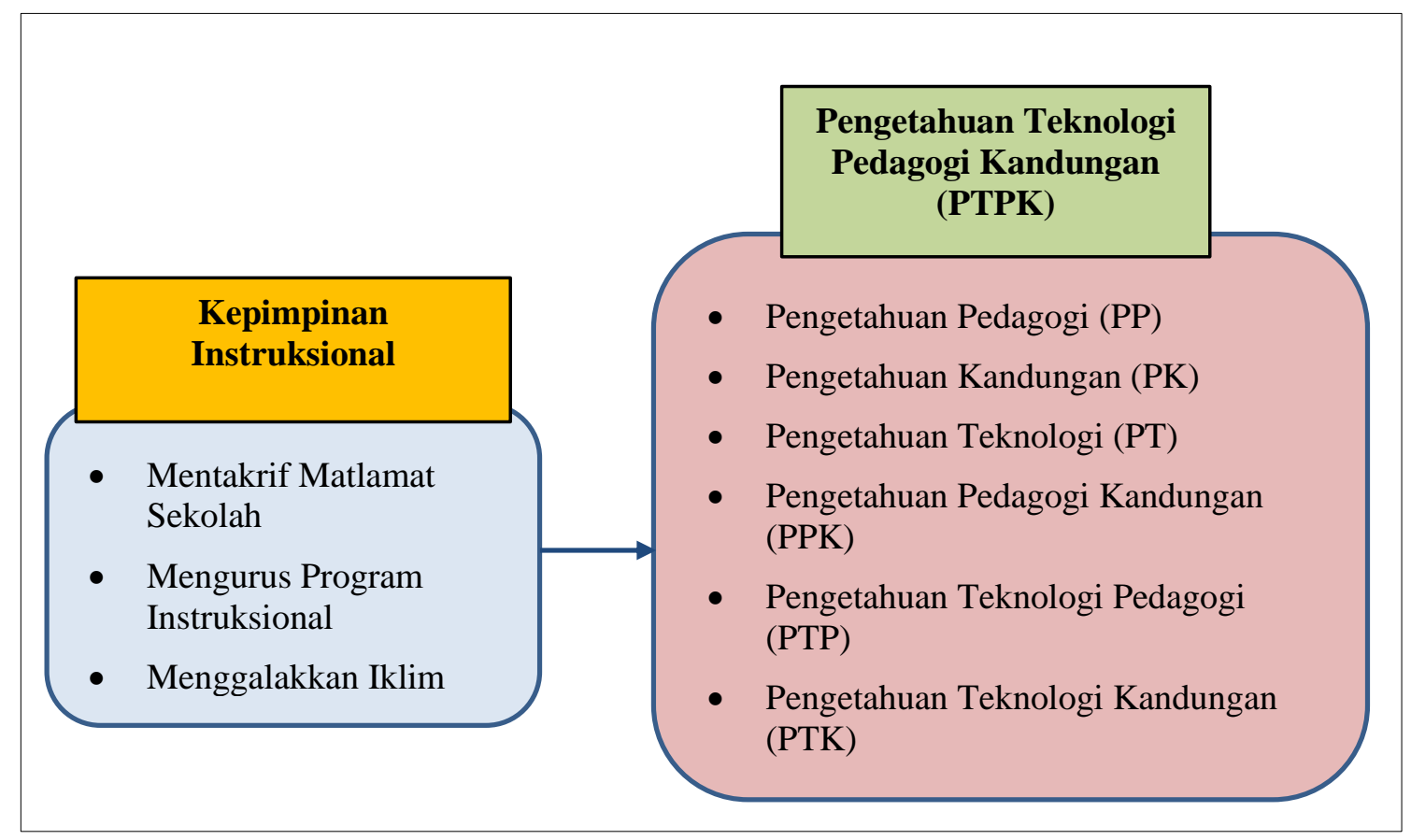

Sumber: Analisis penyelidik 


\section{Kesimpulan}

Kertas konsep ini menekankan hubungan di antara amalan kepimpinan instruksional pemimpin di sekolah dengan pengintegrasian teknologi dalam pengajaran guru. Pemilihan kedua-dua elemen ini iaitu kepimpinan instruksional dan juga PTPK ini adalah selaras dengan objektif kajian. Hasil kajian literatur menunjukkan terdapat saling perkaitan di antara kedua-dua elemen ini. Oleh itu, kajian ini memfokuskan perubahan kepimpinan instruksional dalam mempengaruhi pengetahuan teknologi pedagogi kandungan. Faktor kepimpinan instruksional bersandarkan model kepimpinan instruksional, manakala pengetahuan teknologi pedagogi kandungan bersandarkan kepada model PTPK.

\section{Rujukan}

Aad, G. et al. (2014). Hubungan Antara Sikap, Minat, Pengajaran Guru Dan Pengaruh Rakan Sebaya Terhadap Pencapaian Matematik Tambahan Tingkatan 4. Jurnal Kurikulum \& Pengajaran Asia Pasifik, 72(12), 1-10. https://doi.org/10.1140/epjc/s10052-012-2241-5

Afshari, M., Abu Bakar, K., Luan, W. S., Abu Samah, B., \& Fooi, F. S. (2008). School leadership and information communication technology. Turkish Online Journal of Educational Technology, 7(4), $82-91$.

Aksal, F. A. (2015). Are headmasters digital leaders in school culture? Education and Science, 40(182), 77-86. https://doi.org/10.15390/EB.2015.4534

Amels, J., Krüger, M., \& van Veen, K. (2020). Relationships in distributed leadership, inquiry-based working, and realizing educational change in Dutch primary education: teachers' and their school leader's perceptions. International Journal of Leadership in Education, 00(00), 1-20. https://doi.org/10.1080/13603124.2020.1842505

Andyani, H., Setyosari, P., Wiyono, B. B., \& Djatmika, E. T. (2020). Does technological pedagogical content knowledge impact on the use of ICT in pedagogy? International Journal of Emerging Technologies in Learning, 15(3), 126-139. https://doi.org/10.3991/ijet.v15i03.11690

Arokiasamy, A. R., Abdullah, A. G. K., \& Ismail, A. (2014). Correlation between cultural perceptions, leadership style and ICT usage by school principals in Malaysia. Turkish Online Journal of Educational Technology, 13(3), 27-40. https://doi.org/10.1016/j.sbspro.2015.01.478

Barton, E. A., \& Dexter, S. (2020). Sources of teachers' self-efficacy for technology integration from formal, informal, and independent professional learning. Educational Technology Research and Development, 68(1), 89-108. https://doi.org/10.1007/s11423-019-09671-6

Blonder, R., \& Rap, S. (2017). I like Facebook: Exploring Israeli high school chemistry teachers' TPACK and self-efficacy beliefs. Education and Information Technologies, 22(2), 697-724. https://doi.org/10.1007/s10639-015-9384-6

Cathrine Masingan, \& Sabariah Sharif. (2019). Pengetahuan Pedagogi Kandungan (PPK) Guru Bukan Pengkhususan Reka Bentuk dan Teknologi (RBT) di Sekolah Menengah. Malaysian Journal of Social Sciences and Humanities (MJ - SSH), 4(6), 64-71.

Clark-Wilson, A., Robutti, O., \& Thomas, M. (2020). Teaching with digital technology. ZDM Mathematics Education, 52(7), 1223-1242. https://doi.org/10.1007/s11858-020-01196-0

Divaharan, S., \& Ping, L. C. (2010). Secondary school socio-cultural context influencing ICT integration: a case study approach factors that affect effective ICT integration. Australasian Journal of Educational Technology, 26(6), 741-763.

Domeny, J. V. (2017). The relationship between digital leadership and digital implementation in elementary schools. ProQuest Dissertations and Theses, 131. https://search.proquest.com/docview/1896954900?accountid=10673\%0Ahttp://openurl.ac.uk/redi rect/athens:edu/?url_ver=Z39.88-

2004\&rft_val_fmt=info:ofi/fmt:kev:mtx:dissertation\&genre=dissertations+\%26+theses\&sid=Pro Q:ProQuest+Dissertations+\%26+Theses+Global\&a

Dooley, C. M. M., Lewis Ellison, T., Welch, M. M., Allen, M., \& Bauer, D. (2016). Digital participatory pedagogy: Digital participation as a method for technology integration in curriculum. Journal of Digital Learning in Teacher Education, 32(2), 52-62. https://doi.org/10.1080/21532974.2016.1138912

Hallinger, P, \& Murphy, J. (1987). Assessing and developing principal instructional leadership. 

DOI: https://doi.org/10.47405/mjssh.v6i11.1158

Educational Leadership, 9(January 1987), 54-61. http://www.ascd.org/ASCD/pdf/journals/ed_lead/el_198709_hallinger.pdf

Hallinger, Philip. (2018). Principal instructional leadership. In The Wiley Handbook of Teaching and Learning. https://doi.org/10.1002/9781118955901.ch21

Hallinger, Philip, \& Hosseingholizadeh, R. (2020). Exploring instructional leadership in Iran: a mixed methods study of high- and low-performing principals. Educational Management Administration and Leadership, 48(4), 595-616. https://doi.org/10.1177/1741143219836684

Hallinger, Phillip, Wang, W. C., \& Chen, C. W. (2013a). Assessing the measurement properties of the principal instructional management rating scale: A meta-analysis of reliability studies. $\begin{array}{llll}\text { Educational Administration } & \text { Quarterly, } & \text { 49(2), }\end{array}$ https://doi.org/10.1177/0013161X12468149

Hallinger, Phillip, Wang, W. C., \& Chen, C. W. (2013b). Assessing the Measurement Properties of the Principal Instructional Management Rating Scale: A Meta-Analysis of Reliability Studies. Educational Administration Quarterly, 49(2), 272-309. https://doi.org/10.1177/0013161X12468149

Hamzah, M. I. M., \& Jamil, M. F. (2019). The Relationship of Distributed Leadership and Professional Learning Community. Creative Education, 10(12), 2730-2741. https://doi.org/10.4236/ce.2019.1012199

Hamzah, N. H., M Nasir, M. K., \& Abdul Wahab, J. (2021). The effects of principals' digital leadership on teachers' digital teaching during the covid-19 pandemic in Malaysia. Journal of Education and E-Learning Research, 8(2), 216-221. https://doi.org/10.20448/journal.509.2021.82.216.221

Harris, A., Jones, M., Adams, D., \& Cheah, K. (2018). Instructional leadership in Malaysia: a review of the contemporary literature. School Leadership and Management, 39(1), 76-95. https://doi.org/10.1080/13632434.2018.1453794

Hassan, R., Ahmad, J., \& Boon, Y. (2018). Instructional leadership in Malaysia. International Journal of Engineering and Technology(UAE), 7(3.30 Special Issue 30), 424-432. https://doi.org/10.14419/ijet.v7i3.30.18346

Hassan, R., \& Jamilah Ahmad, Y. B. (2019). Instructional Leadership in Malaysia. Educational Management Administration and Leadership, 8(2), 537-547. https://doi.org/10.1177/1741143219836684

Heck, R. H., \& Hallinger, P. (2014). Modeling the longitudinal effects of school leadership on teaching and learning. Journal of Educational Administration, 52(5), 653-681. https://doi.org/10.1108/JEA-08-2013-0097

Hussin, S. S. A. M. B. \& M. (2019). International Conference on Global Education VII “ Humanising Technology For IR 4 . 0 " International Conference on Global Education VII. International Conference on Global Education VII "Humanising Technology For IR 4.0," 2002, 1-2.

Ismail, S. N., Don, Y., Husin, F., \& Khalid, R. (2018). Instructional leadership and teachers' functional competency across the 21st century learning. International Journal of Instruction. https://doi.org/10.12973/iji.2018.11310a

Karahan, E., Canbazoglu Bilici, S., \& Unal, A. (2015). Integration of media design processes in Science, Technology, Engineering, and Mathematics (STEM) education. Egitim Arastirmalari Eurasian Journal of Educational Research, 60, 221-240. https://doi.org/10.14689/ejer.2015.60.15

Kementerian PendidikanMalaysia. (2015). Pelan Pembangunan Pendidikan Malaysia 2015- 2025 (Pendidikan Tinggi). In Kementerian Pendidikan Malaysia.

Koehler, M. J., Mishra, P., Kereluik, K., Shin, T. S., \& Graham, C. R. (2014). The technological pedagogical content knowledge framework. In Handbook of Research on Educational Communications and Technology: Fourth Edition. https://doi.org/10.1007/978-1-4614-3185-5_9

M. N., M. K., \& Quick, D. (2016). Teaching presence influencing online students' course satisfaction at an institution of higher education. International Education Studies, 9(3), 62. https://doi.org/10.5539/ies.v9n3p62

Ma, X., \& Marion, R. (2021). Exploring how instructional leadership affects teacher efficacy: A multilevel analysis. Educational Management Administration and Leadership, 49(1), 188-207. https://doi.org/10.1177/1741143219888742

Mayes, R., Natividad, G., \& Spector, J. M. (2015). Challenges for educational technologists in the 21st 
century. Education Sciences, 5(3), 221-237. https://doi.org/10.3390/educsci5030221

Mei Wei, L., Chua, Y. P., \& Kannan, S. (2016). Relationship between principal technology leadership practices and teacher ICT competency. Malaysian Online Journal of Educational Management, 4(3), 13-36. https://doi.org/10.22452/mojem.vol4no3.2

Mishra, P., \& Koehler, M. J. (2006). Technological Pedagogical Content Knowledge (TPACK) Framework - Educational Technology. Teachers College Record.

Mlambo, S., Rambe, P., \& Schlebusch, L. (2020). Effects of Gauteng province's educators' ICT selfefficacy on their pedagogical use of ICTS in classrooms. Heliyon, 6(4), e03730. https://doi.org/10.1016/j.heliyon.2020.e03730

Niekerk, E. J., \& Wyk, M. M. (2014). Staff's perceptions of vision and long term principal leadership in South African schools: an exploratory study. Mediterranean Journal of Social Sciences, 5(4), 406-414. https://doi.org/10.5901/mjss.2014.v5n4p406

OECD. (2021). 21st-Century Readers: Developing Literacy Skills in a Digital World. www.oecd.org/about/publishing/corrigenda.htm. (C)

Pozo, J. I., Pérez Echeverría, M. P., Cabellos, B., \& Sánchez, D. L. (2021). Teaching and Learning in Times of COVID-19: Uses of Digital Technologies During School Lockdowns. Frontiers in Psychology, 12(April), 1-13. https://doi.org/10.3389/fpsyg.2021.656776

Qadach, M., Schechter, C., \& Da'as, R. (2020). From principals to teachers to students: exploring an integrative model for predicting students' achievements. Educational Administration Quarterly, 56(5), 736-778. https://doi.org/10.1177/0013161X20907133

Raman, A., Thannimalai, R., \& Ismail, S. N. (2019). Principals' technology leadership and its effect on teachers' technology integration in 21st century classrooms. International Journal of Instruction, 12(4), 423-442. https://doi.org/10.29333/iji.2019.12428a

Shulla, K., Voigt, B.-F., Cibian, S., Scandone, G., Martinez, E., Nelkovski, F., \& Salehi, P. (2021). Effects of COVID-19 on the Sustainable Development Goals (SDGs). Discover Sustainability, 2(1). https://doi.org/10.1007/s43621-021-00026-x

Shulman, L. S. (1986). Those Who Understand: Knowledge Growth in Teaching. Educational Researcher. https://doi.org/10.2307/1175860

Sun, J., \& Leithwood, K. (2017). Calculating the power of alternative choices by school leaders for improving student achievement. School Leadership and Management, 37(1-2), 80-93. https://doi.org/10.1080/13632434.2017.1293635

Tibagwa, K. N., Onen, D., \& Oonyu, J. (2016). Head teacher' s leadership styles and the quality of teacher support supervision. International Journal of Education and Research, 4(8).

Vazquez Cano, E., \& Sevillano García, M. L. (2013). ICT strategies and tools for the improvement of instructionals supervision. The virtual supervision. Turkish Online Journal of Educational Technology, 12(1), 77-87.

Vinathan, T. (2017). Hubungan motivasi guru dengan penggunaan ICT dalam pengajaran di SJK (T) daerah Kuala Muda Yan. Proceedings of the ICECRS, I(1), 1043-1054. https://doi.org/10.21070/picecrs.v1i1.647

Yusof, M. R., Mohd Yaakob, M. F., \& Ibrahim, M. Y. (2019). Digital leadership among school leaders in Malaysia. International Journal of Innovative Technology and Exploring Engineering, 8(9), 1481-1485. https://doi.org/10.35940/ijitee.i8221.078919

Zhong, L. (2017). Indicators of digital leadership in the context of K-12 education. Journal of Educational Technology Development and Exchange, 10(1). https://doi.org/10.18785/jetde.1001.03 